\title{
Pelatihan Pembuatan Materi Presentasi Sebagai Bekal Persiapan Memasuki Dunia Kerja Bagi Siswa SMK Abdi Negara 2 Cibarusah
}

\author{
Nuraini Purwandari' ${ }^{1)}$, Ridha Sefina Samosir'²), Arie Kusumawati ${ }^{3)}$ \\ Sistem Informasi, Fakultas Industri Kreatif Institut Teknologi dan Bisnis Kalbis \\ Jalan Pulomas Selatan Kav.22, Jakarta Timur 13210 \\ ${ }^{1)}$ Email: nuraini.purwandari@kalbis.ac.id \\ ${ }^{2)}$ Email: ridha.samosir@kalbis.ac.id \\ ${ }^{3)}$ Email: arie.kusumawati@kalbis.ac.id
}

\begin{abstract}
Abdi Negara 2 Cibarusah Vocational School is a private school from Bekasi Abdi Negara Education Foundation. There are 4 expertise programs in the Vocational School, namely Electric Power Installation Engineering, Light Vehicle Automation Engineering, Office Administration, and Accounting. To support students' expertise, skills in managing office administration are certainly needed, including using the Microsoft Office program. There are various kinds of data processing applications today, one of which is the Microsoft Power Point presentation application program. . Therefore, the power of Microsoft Power Point is very important in the teaching and learning process at this time. However, there are still many Abdi Negara 2 vocational students who have not mastered these applications, especially the Power Point application. The purpose of this training is to provide basic knowledge to students about Microsoft Power Point computer applications to make simple, interactive presentations and introduce basic commands to make presentations to make students more attractive in order to improve students' professionalism as a preparation for entering the workforce. The results of this training are in the form of material training presentation and documentation.
\end{abstract}

Keywords: training, presentations, students, vocational schools, Microsoft Power Point

\begin{abstract}
Abstrak: SMK Abdi Negara 2 Cibarusah adalah sekolah swasta dari Yayasan Pendidikan Abdi Negara Bekasi. Program keahlian yang terdapat pada SMK ini ada 4 program, yaitu Teknik Instalasi Tenaga Listrik, Teknik Otomitif Kendaraan Ringan, Administrasi Perkantoran, dan Akuntansi. Untuk menunjang keahlian siswa tentunya diperlukan keterampilan dalam mengelola administrasi perkantoran, diantaranya menggunakan progam Microsoft Office. Terdapat berbagai macam aplikasi pengolahan data saat ini, salah satunya adalah program aplikasi presentasi Microsoft Power Point. Oleh karena itu, peguasaan Microsoft Power Point sangat penting dalam proses belajar mengajar pada saat ini. Namun siswa-siswa SMK Abdi Negara 2 saat ini masih banyak yang belum menguasai aplikasi-aplikasi tersebut terutama aplikasi Power Point. Tujuan pelatihan ini adalah memberikan pengetahuan dasar kepada siswa tentang aplikasi komputer Microsoft Power Point untuk membuat presentasi sederhana yang interaktif dan mengenalkan perintah dasar membuat presentasi agar lebih menarik siswa dalam rangka meningkatkan profesionalisme para siswa sebagai bekal persiapan memasuki dunia kerja.Hasil dari pelatihan ini berupa materi presentasi dan dokumentasi pelatihan.
\end{abstract}

Kata kunci: pelatihan, presentasi, siswa, SMK, Microsoft Power Point

\section{PENDAHULUAN}

Sekolah Menengah Kejuruan (SMK) adalah salah satu bentuk satuan pendidikan formal yang menyelenggarakan pendidikan kejuruan pada jenjang pendidikan menengah sebagai lanjutan dari SMP/MTs atau bentuk lain yang sederajat atau lanjutan dari hasil belajar yang diakui sama/setara
SMP/MTs. Di SMK terdapat banyak sekali Program Keahlian. Sekolah Menengah Kejuruan (SMK) Abdi Negara 2 Cibarusah terletak di Jl. Raya Cikarang Cibarusah Km 11, Desa Sindang Mulya, Kecamatan Cibarusah, Provinsi Jawa Barat. SMK Abdi Negara 2 Cibarusah adalah sekolah swasta dari Yayasan Pendidikan Abdi Negara Bekasi. Berdiri tahun 2004 yaitu tanggal 19 Juli 2004 dan pada saat ini statusnya 
terakreditasi A. Program keahlian yang terdapat pada SMK ini ada 4 program, yaitu Teknik Instalasi Tenaga Listrik, Teknik Otomitif Kendaraan Ringan, Administrasi Perkantoran, dan Akuntansi. Guru yang mengajar berjumlah 41 orang dan siswanya pada saat ini berjumlah 647 orang. Fasilitas yang dimiliki antara lain: Ruang kelas, perpustakaan, lapangan olah raga, laboratorium dan ruang praktek. Khusus untuk laboratorium komputer, SMK ini memiliki 3 buah laboratorium komputer yang masing-masing laboratorium komputer terdapat sejumlah 30 unit.

Administrasi Perkantoran adalah salah satu program keahlian pada SMK Abdi Negara 2 Cibarusah. Banyak hal yang dipelajari di jurusan ini yang nantinya akan membentuk lulusan yang dapat bekerja pada bidang antara lain: Junior Secretary, Resepsionis, Humas, Operator peralatan kantor, Juru tata usaha, Pengelola perpustakaan, dan lain-lain. Administrasi Perkantoran adalah kegiatan sehari-hari yang berfokus pada perencanaan anggaran keuangan, pembayaran dan pendataan suatu perkantoran atau perusahaan. Administrasi kantor bertanggung jawab atas merencanakan kegiatan kantor, menyediakan peralatan kantor, mengatur perubahan antar departemen, serta membantu tugas manajemen senior untuk menggaji dan memberhentikan karyawan. Sedangkan Teknik Instalasi Tenaga Listrik, Teknik Otomitif Kendaraan Ringan adalah program keahlian dalam bidang listrik dan otomotif serta jurusan Akuntansi yang merupakan program keahlian dalam manajemen keuangan.

Untuk menunjang keahlian siswa program Administrasi Perkantoran, Teknik Instalasi Tenaga Listrik, Teknik Otomitif Kendaraan Ringan dan Akuntansi, tentunya diperlukan keterampilan dalam mengelola administrasi perkantoran, diantaranya menggunakan progam microsoft office.

Microsoft Office merupakan software aplikasi perkantoran berbasis Windows yang dirancang khusus menyelesaikan pekerjaan administrasi modern yang memiliki tingkat kondisi atau kebutuhan yang berbeda-beda serta tingkat flexibilitas yang tinggi [1]. Program Microsoft Office telah menjadi standar program untuk perkantoran, bisnis dan pendidikan. Keterampilan ini diperlukan oleh guru dan siswa SMK dapat dijadikan sebagai alat bantu di lingkungan kerja atau sebagai media untuk mempermudah proses pengerjaan tugas sehari-hari, sehingga dari pengetahuan yang telah diperoleh tersebut peserta pelatihan ini mampu menggunakannya untuk mengerjakan tugas-tugas seperti membuat dan mengolah dokumen, membuat laporan pembukuan, laporan keuangan, analisa statistik, formulir, database, slide presentasi dan lain-lain. Terdapat berbagai macam aplikasi pengolahan data saat ini, salah satunya adalah program aplikasi presentasi Microsoft Power Point. Dalam penerapannya aplikasi-aplikasi tersebut dapat membantu pelajar dalam menyiapkan presentasi untuk seminar, pelatihan atau persiapan bekal melamar pekerjaan. Oleh karena itu, peguasaan Microsoft Power Point sangat penting dalam proses belajar mengajar pada saat ini. Namun siswa-siswa SMK Abdi Negara 2 saat ini masih banyak yang belum menguasai aplikasi-aplikasi tersebut terutama aplikasi Power Point.

Sehubungan dengan hal tersebut dan dalam rangka mewujudkan salah satu Tri Dharma Perguruan Tinggi yaitu pengabdian kepada masyarakat, program studi Sistem Informasi Kalbis Institute akan mengusulkan program pelatihan bagi siswa SMKN Abdi Negara 2 Cibarusah tentang pembuatan materi presentasi sebagai bekal persiapan memasuki dunia kerja. Tujuan pelatihan ini adalah memberikan pengetahuan dasar kepada siswa tentang aplikasi komputer Microsoft Power Point untuk membuat presentasi sederhana yang interaktif dan mengenalkan perintah dasar membuat presentasi agar lebih menarik siswa dalam rangka meningkatkan profesionalisme para siswa sebagai bekal persiapan untuk memasuki dunia kerja.

Pelatihan kepada siswa SMK Abdi Negara 2 Cibarusah mengenai dasar-dasar Microsoft Power Point sebagai sarana pendukung proses pembelajaran di sekolah dan peningkatan kemampuan siswasiswa bekal persiapan memasuki dunia kerja akan dilaksanakan pada tanggal 10 April 2019 di Jalan Raya Cikarang - Cibarusah KM 11 Desa Sindang Mulya, Kecamatan Cibarusah dengan materi pelatihan Pengenalan Aplikasi Microsoft Office dan Pengoperasian Aplikasi Microsoft Power Point serta Google Slide.

\section{METODE PELAKSANAAN}

\section{A. Metode dan Pendekatan Kegiatan PKM}

Deskripsi kegiatan Pengabdian Kepada Masyarakat yaitu pelatihan untuk siswa SMK Abdi Negara 2 Cibarusah tanggal 10-11 April 2019 sebagai berikut:

\section{B. Observasi Kegiatan PKM}

Observasi ke lokasi mitra PKM ke SMK Abdi Negara 2 Cibarusah yang berlokasi di Jalan Raya Cikarang - Cibarusah KM 11 Ds. Sindang Mulya, 
Kec. Cibarusah tanggal 18 Februari 2017 pukul 14.00 - 17.00 WIB untuk: Perkenalan kegiatan PKM Prodi Sistem Informasi oleh tim PKM kepada mitra; Pengenalan profil SMK Abdi Negara 2 Cibarusah; Pemberian saran-saran dari para dari Kepala Sekolah SMK Abdi Negara 2 Cibarusah agar kegiatan pengabdian masyarakat tepat sasaran dan bermanfaat bagi siswa dan guru; Identifikasi permasalahan spesifik yang sedang dihadapi mitra; Koordinasi tema pelatihan yang dibutuhkan oleh mitra; Koordinasi waktu dan tempat pelaksanaan kegiatan PKM; dan Kerjasama (MOU) di SMK Abdi Negara 2 untuk melakukan kegiatan penelitian maupun Pengabdian Kepada Masyarakat (PKM) selama 5 tahun.

\section{Sosialisasi Program Kerja Program Studi}

Sosialisasi didiskusikan dalam rapat Tim Dosen Program Studi Sistem Informasi Fakultas Industri Kreatif Institut Teknologi dan Bisnis Kalbis pada 15 Oktober 2018 pukul 14.00 - 16.00 WIB di ruang dosen Lantai 2 Kampus Institut Teknologi dan Bisnis Kalbis, Jalan Pulomas Selatan Kav.22 Jakarta Timur. Rapat ini untuk membicarakan salah satu program kerja Prodi adalah mengadakan kegiatan Pengabdian Kepada Masayarakat (PKM) sebanyak dua kali per tahun. Hasil dari sosialisasi program kerja ini berupa jadwal pelaksanaan PKM adalah bulan April 2019 dan bulan Oktober 2019.

\section{Koordinasi tim PKM dengan Kepala Sekolah SMK Abdi Negara 2 Cibarusah}

KoordinasitimPKMdilakukanmelaluiwhatsapp dengan Kepala Sekolah Bapak Mus Mulyadi pada tanggal 18 - 22 Februari 2019 pukul $10.00-12.00$ WIB. Hasil koordinasi ini membicarakan tentang rencana tim PKM akan melakukan kegiatan pelatihan untuk siswa SMK Abdi Negara 2 dengan topik dan judul yang nantinya akan ditetapkan selanjutnya.

\section{E. Koordinasi Program Studi}

Koordinasi ketiga Prodi yaitu Sistem Informasi, Ilmu Komunikasi, dan Matematika dilakukan pada tanggal 25 Februari 2019 pukul 15.00 - 17.00 WIB di ruang dosen Lantai 2 Kampus Institut Teknologi dan Bisnis Kalbis, Jalan Pulomas Selatan Kav.22 Jakarta Timur. Hasil koordinasi ini adalah penentuan anggota tim PKM dan topik judul PKM yang akan diajarkan kepada siswa SMK Abdi Negara 2 Cibarusah.

\section{F. Perencanaan Kegiatan PKM di SKM Abdi Negara 2 Cibarusah}

Rencana ini didiskusikan dalam rapat Tim Dosen Program Studi Sistem Informasi Fakultas
Industri Kreatif Institut Teknologi dan Bisnis Kalbis yang tergabung kedalam Tim Pengabdian Kepada Masyarakat (PKM) pada 27 Februari 2019 pukul 14.00 - 17.00 WIB di ruang dosen Lantai 2 Kampus Institut Teknologi dan Bisnis Kalbis, Jalan Pulomas Selatan Kav.22 Jakarta Timur. Diskusi ini untuk membicarakan PKM yang merupakan salah satu wujud Tri Dharma Perguruan Tinggi. Hasilnya adalah kesepakatan untuk melakukan PKM dengan mitra SMK Abdi Negara 2 Cibarusah.

\section{G. Sosialisasi Rencana Kegiatan PKM}

Setelah didapatkan informasi dari hasil observasi ke SMK Abdi Negara 2 Cibarusah, maka Prodi Sistem Informasi melaksanakan rapat sosialisasi perencanaan kegiatan PKM pada tanggal 4 Maret 2019 pukul 13.00 - 16.00WIB di ruang Yudhistira Lantai 2 Institut Teknologi dan Bisnis Kalbis. Pada rapat ini disosialisasikan road map kegiatan PKM pada Prodi Sistem Informasi untuk Semester Genap 2018/2019.

\section{H. Pembuatan Proposal PKM}

Pembuatan Proposal "Pelatihan Pembuatan Materi Presentasi Sebagai Bekal Persiapan Memasuki Dunia Kerja Bagi Siswa SMK Abdi Negara 2 Cibarusah" tanggal 11-14 Maret 2019 pukul 09.00 11.00 WIB oleh tim PKM.

\section{Pembuatan Materi Pelatihan PKM}

Pembuatan materi "Pelatihan Pembuatan Materi Presentasi Sebagai Bekal Persiapan Memasuki Dunia Kerja Bagi Siswa SMK Abdi Negara 2 Cibarusah" tanggal 18-21 Maret 2019 pukul 15.00 - 17.00 WIB oleh tim PKM.

\section{J. Rapat Tim Persiapan Dan Perlengkapan PKM}

Rapat tim dan persiapan dan perlengkapan PKM pada tanggal 09 April 2019 pukul 09.00 12.00 WIB. Kegiatan ini adalah mempersiapkan semua perlengkapan PKM seperti cetak spanduk, penggandaan materi pelatihan, persiapan kendaraan menuju lokasi, pembuatan surat-surat yang dibutuhkan untuk kegiatan PKM, dan lain-lain. Kemudian dilakukan juga rapat semua anggota yang akan berangkat ke lokasi PKM, briefing mahasiswa serta pendalaman materi pelatihan

\section{K. Pelaksanaan Kegiatan PKM}

Kegiatan pelatihan diadakan selama dua hari yaitu tanggal 10-11 April 2019 pukul $09.00-17.00$ WIB, bertempat di SMK Abdi Negara 2 Cibarusah. Pelatihan diberikan oleh Tim PKM dari Prodi Sistem 
Informasi, Ilmu Komunikasi dan Matematika yang berjumlah sebanyak satu ketua, dua orang dosen dan dua mahasiswa. Peserta pelatihan adalah siswa SMK Abdi Negara 2 Cibarusah yang terdiri dari 25 orang.

Acara dimulai dengan melakukan registrasi peserta pada pukul $08.00-09.00 \mathrm{WIB}$, dilanjutkan pembukaan oleh MC yang diwakilkan dari staff guru SMK Abdi Negara 2 Cibarusah. Pada acara pembukaan $\mathrm{MC}$ memperkenalkan jajaran staff dan guru serta peserta siswa-siswi SMK Abdi Negara 2 yang mengikuti acara pelatihan. Pukul $09.00-$ 09.15 WIB dilanjutkan dengan sambutan oleh Mus Mulyadi, SE selaku Kepala Sekolah SMK Abdi Negara 2 Cibarusah. Dalam sambutannya beliau mengucapkan terima kasih atas kehadiran tim PKM Kalbis Insitute dalam membantu upaya meningkatkan kualitas siswa-siswi SMK Abdi Negara 2 Cibarusah.

Pukul 09.15 - 09.30 sambutan oleh Ibu Ridha Sefina Samosir, S.Si., M.Kom selaku Ketua Program Studi Sistem Informasi Kalbis Institute. Dalam sambutannya, Ibu Ridha Sefina Samosir, S.Si., M.Kom memperkenalkan tim PKM yang terdiri dari Dosen dan Mahasiswa Kalbis Institute kepada peserta pelatihan bahwa kegiatan pengabdian kepada masyarakat merupakan salah satu Tri Dharma Perguruan Tinggi. Beliau juga mengucapkan terima kasih atas kehadiran dan partisipasi siswa SMK Abdi Negara 2 yang telah mendukung kegiatan pengabdian kepada masyarakat dengan harapan semoga kegiatan ini nantinya dapat memberikan manfaat bagi para siswa dalam meningkatkan kualitas sumber daya manusia dan proses pembelajaran di sekolah.

Pukul 09.30 - 11.00 WIB acara dilanjutkan dengan pelatihan Modul 1 dan 2 yaitu "Pelatihan Pembuatan Materi Presentasi Sebagai Bekal Persiapan Memasuki Dunia Kerja Bagi Siswa SMK Abdi Negara 2 Cibarusah " dengan instruktur Muhammad Aldo. Pada modul 1 peserta diperkenalkan dengan aplikasi Microsoft Power Point 2007 untuk membuka aplikasi dan mengenalkan tampilan Microsoft Power Point 2007. Pada modul 1 materi yang dibawakan oleh saudara Muhammad Aldo adalah : Pengenalan Interface/Tampilan Power Point 2007; Membuat dokumen baru dalam Microsoft Power Point 2007; Memulai sebuah presentasi dari template; Bekerja dalam objek gambar; Bekerja dengan objek shape; dan Bekerja dalam Animasi, Media dan Sound

Pukul 11.00 - 12.00 WIB acara dilanjutkan dengan pelatihan Modul 2 yaitu "Pelatihan Pembuatan Materi Presentasi Sebagai Bekal Persiapan Memasuki Dunia Kerja Bagi Siswa SMK Abdi Negara 2 Cibarusah" dengan instruktur Ibu Nuraini Purwandari.
Pada modul 2 peserta diajarkan mengenai pembuatan tabel pada Microsoft Power Point 2007. Pada modul 2 materi yang dibawakan oleh Ibu Nuraini adalah: Bekerja dalam tabel; Memilih tabel, sel, baris dan kolom; Mengatur style tabel; dan Mengubah desain tabel sesuai yang diinginkan.

Setelah istirahat untuk makan siang dan ibadah pukul 12.00 - 13.00 WIB acara kembali dilanjutkan dengan pelatihan modul berikutnya.

Pukul 13.00 - 14.30 WIB acara dilanjutkan dengan pelatihan Modul 3 yaitu "Pelatihan Pembuatan Materi Presentasi Sebagai Bekal Persiapan Memasuki Dunia Kerja Bagi Siswa SMK Abdi Negara 2 Cibarusah" dengan instruktur Ibu Ridha Sefina Samosir. Pada modul 3 peserta diajarkan cara menambahkan grafik ke dalam slide. Pada modul 3 materi yang dibawakan oleh Ibu Ridha adalah: Bekerja dalam grafik; Mengatur format diagram dalam presentasi; Mengatur legend/keterangan grafik; Mengubah layout grafik; dan Mengubah background grafik yang sesuai.

Pukul 14.30 - 15.30 WIB acara dilanjutkan dengan pelatihan Modul 4 yaitu "Pelatihan Pembuatan Materi Presentasi Sebagai Bekal Persiapan Memasuki Dunia Kerja Bagi Siswa SMK Abdi Negara 2 Cibarusah" dengan instruktur Bapak Arie Kusumawati. Pada modul 4 peserta diajarkan mengenai pembuatan tampilan outline dalam slide. Pada modul 4 materi yang dibawakan oleh Bapak Harfebi adalah: Bekerja dalam tampilan outline; Mengubah slide ke tampilan outline; Mengatur format teks outline; dan Menyimpan outline

Pukul 15.30 - 16.30 WIB acara dilanjutkan dengan pelatihan Modul 5 yaitu "Pelatihan Pembuatan Materi Presentasi Sebagai Bekal Persiapan Memasuki Dunia Kerja Bagi Siswa SMK Abdi Negara 2 Cibarusah" dengan instruktur Arindra Alifianto. Pada modul 5 peserta diajarkan tentang menambahkan hyperlink dan action button ke dalam slide. Pada modul 5 materi yang dibawakan Arindra Alifianto adalah: Bekerja dalam hyperlink dan action button; Membuat hyperlink antar file; Mengubah hyperlink; dan Membuat action button dari objek shape

Pukul 16.30 - 16.45 WIB acara dilanjutkan dengan pemberian pelatihan yang dipandu oleh Muhammad Aldo (Mahasiwa Prodi Sitem Informasi) dengan instruktur tim dosen yang tergabung kedalam tim PKM secara bergantian. Disini peserta pelatihan juga diberikan kesempatan untuk bertanya mengenai modul pelatihan yang telah diberikan dan melakukan presentasi tentang aplikasi Microsoft Power Point. Pada sesi ini terlihat semua peserta sangat 
antusias dengan materi pelatihan yang diberikan. Keingintahuan peserta terlihat dari banyaknya pertanyaan yang diajukan pada sesi ini.

Pukul 16.45 - 17.00 WIB pada akhirnya acara pelatihan diakhiri oleh Ketua Pelaksana PKM yaitu Ibu Nuraini Purwandari,ST., M.M.S.I dengan foto bersama seluruh peserta.

Pada tanggal 11 April 2019 dilakukan kegiatan PKM hari kedua yang terdiri dari dosen-dosen Prodi Sistem Informasi, Ilmu Komunikasi dengan tema pembuatan video scribe dan public speaking. Kegiatan pelatihan dimulai dari pukul 09.00-17.00 yang diakhiri dengan pemberian sertifikat kepada semua peserta dan penutupan acara kegiatan PKM.

Pelaksanaan kegiatan pelatihan yang dilaksanakan pada tanggal 10-11 April 2019 pukul 09.00 sampai dengan 17.00 di Gedung SMK Abdi Negara 2 Cibarusah ditunjukkan dengan surat Keterangan No.009/A.U/SMK.AN2/IV/2019 yang ditandatangani oleh Kepala Sekolah SMK Abdi Negara 2 yaitu Bapak Mus Mulyadi, SE.

\section{HASIL DAN PEMBAHASAN}

\section{A. Pengertian Presentasi}

Presentasi merupakan kegiatan yang penting dalam mengkomunikasikan suatu gagasan kepada orang lain dengan berbagai tujuan, misalnya untuk menarik audiensi agar mereka membeli produk, menggunakan jasa atau untuk kepentingan lain. Salah satu alat peraga yang dapat digunakan untuk mendukung presentasi adalah komputer. Adapun salah satu perangkat lunak yang dapat dipakai adalah PowerPoint yang merupakan bagian dari Microsoft Office. Microsoft PowerPoint adalah suatu software yang akan membantu dalam menyusun sebuah presentasi yang efektif, professional, dan juga mudah. Microsoft PowerPoint akan membantu sebuah gagasan menjadi lebih menarik dan jelas tujuannya jika dipresentasikan karena Microsoft PowerPoint akan membantu dalam pembuatan slide, outline presentasi, presentasi elektronika, menampilkan slide yang dinamis, termasuk clip art yang menarik, yang semuanya itu mudah ditampilkan di layar monitor komputer. [2]

\section{B. Perbedaan Microsoft Office 2003, 2007 dan 2010}

Bagi yang terbiasa menggunakan Microsoft Office 2003, mungkin akan sedikit kesulitan ketika menggunakan Office 2007, atau lebih lagi ketika menggunakan Microsoft Office 2010. Ada banyak perubahan yang dilakukan Microsoft sebagai pengembang aplikasi Office yang dimaksudkan agar setiap penggunanya dapat memanfaatkan fitur-fitur baru dan beberapa fitur lama yang lebih. Perbedaan yang paling menonjol diantara kedua versi tersebut bisa dilihat dari segi tampilan, layout dan tata letak dari menu. Perubahan itu nyatanya malah membuat orang jadi bingung karena harus meluangkan waktu lagi agar bisa beradaptasi dengan tampilan yang baru. Karena bingung dengan tampilan baru, beberapa orang lebih memilih untuk menguninstall kembali Office 2007, kemudian kembali menggunakan versi lama yaitu Office 2003. Menginstall software lama juga bukan merupakan solusi terbaik mengingat anda mungkin akan sering bertukar file dengan orang lain yang menggunakan Office 2007. Bisa dipastikan, data Word, Excel, Access, PowerPoint teman anda tidak akan terbaca karena anda masih menggunakan Microsoft Office 2003. [3]

Adapun perbedaan Microsoft PowerPoint 2003, 2007, 2010, yaitu:

Microsoft Powerpoint 2003: a) Berupa tampilan menu dan toolbar pada jendela program; b) Fungsi dan pilihan di PowerPoint 2003 dapat diakses melalui menu dan toolbar di bagian atas jendela program. c. Ekstensi file untuk PowerPoint 2003 adalah pps ppt untuk presentasi dan untuk pertunjukan PowerPoint; dan d) Tidak banyak memiliki template baru ataupun fitur-fitur baru, misalnya Reflection pada WordArt, Real 3D-Rotation.

Microsoft PowerPoint 2007: a) Tampilan menu dan toolbar diubah menjadi ribbon yang terdiri dari tabs, groups, dan tombol perintah; b) PowerPoint 2007 memanfaatkan toolbar utama yang mengandung fungsi tab atau dikelompokkan untuk akses cepat dan disesuaikan, ditambah dengan tombol Office untuk file dan pilihan aplikasi (seperti menyimpan dan mengekspor); c) Office 2007 program dapat diintegrasikan untuk mencerminkan perubahan antara file terkait. Sebagai contoh, sebuah grafik Excel tertanam dalam slide PowerPoint akan mencerminkan perubahan data; dan d) Office $2007 \mathrm{SP}$ 2 sudah mendukung format/eksistensi .odt dan .pdf.

Microsoft Powerpoint 2010: a) Microsoft Office 2010 di claim lebih cepat start-upnya dibandingkan 2007. Selain lebih cepat Office 2010 terbagi menjadi aplikasi 64 bit (x64) dan 32 bit (x86); b) Ribbon di 2010 lebih simple dan enak dilihat. Hampir sama persis, namun pada setiap tombol-tombol di ribbon tidak diberi kotak atau separator sehingga terlihat lebih lenggang dan lebih mudah dicari tomboltombol yang kita inginkan; dan c) Di Office 2010 fitur 
SmartArt memiliki lebih banyak diagram dan lebih banyak opsi untuk diedit. [4]

\section{Jenis Mitra}

Kegiatan Pengabdian Masyarakat dilakukan pada sebuah lembaga pendidikan yaitu SMK Abdi Negara 2 Cibarusah yang memiliki Jurusan Administrasi Perkantoran, Akutansi, Teknik Otomotif Kendaraan Ringan, Teknik Instalasi Tenaga Listrik.

\section{Jumlah Mitra}

Jumlah mitra yang terlibat dalam kegiatan Pengabdian Masyarakat adalah satu mitra lembaga pendidikan yaitu SMK Abdi Negara 2 Cibarusah.

\section{E. Kondisi Mitra}

Pada bagian ini akan dijelaskan profil umum SMK Abdi Negara 2 Cibarusah yang meliputi identitas sekolah, data program keahlian, siswa, guru, dan fasilitas yang dimiliki. dapat dilihat pada Tabel 1 . sampai dengan Tabel 7.

Berdasarkan kondisi mitra yang telah dijelaskan sebelumnya, fasilitas sekolah dapat dilihat pada Gambar 1 Gedung SMK Abdi Negara 2 Cibarusah.

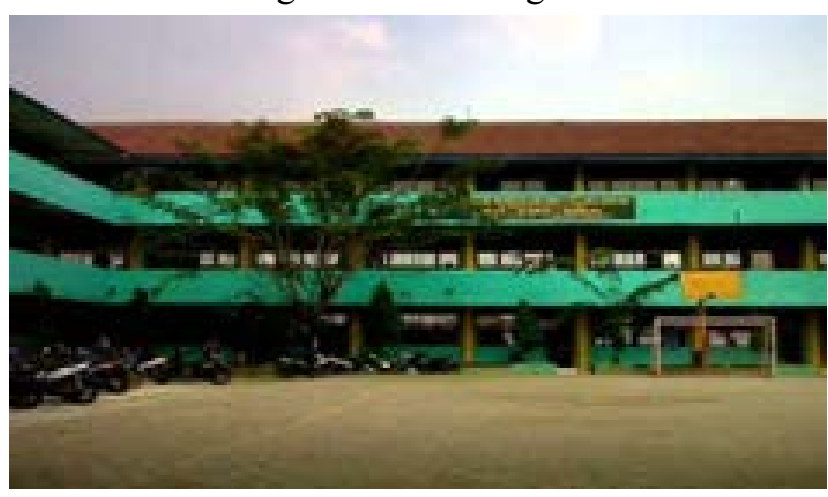

Gambar 2.1 Gedung SMK Abdi Negara 2 Cibarusah

\section{F. Pendidikan Mitra}

Mitra Pengabdian Masyarakat SMK Abdi Negara 2 Cibarusah memiliki guru dan karyawan yang status pendidikannya dapat dilihat pada Tabel 8 dan Tabel 9.

\section{G. Persoalan Mitra}

Persoalan mitra saat ini adalah menyiapkan bekal kepada siswa-siswa SMK Abdi Negara 2 untuk melamar pekerjaan. Terdapat berbagai macam aplikasi pengolahan data saat ini, salah satunya adalah program aplikasi presentasi Microsoft Power Point. Dalam penerapannya aplikasi-aplikasi tersebut dapat membantu pelajar dalam menyiapkan presentasi untuk seminar, pelatihan atau persiapan
Tabel 1. Identitas sekolah

\begin{tabular}{|c|c|}
\hline Nama Sekolah & : SMK Abdi Negara 2 Cibarusah \\
\hline Nama Kepala Sekolah & : Mus Mulyadi, SE \\
\hline $\begin{array}{l}\text { Wakil Kepala Sekolah Bidang } \\
\text { Kesiswaan }\end{array}$ & : Rudi Hartono, S.Kom. \\
\hline $\begin{array}{l}\text { Wakil Kepala Sekolah Bidang } \\
\text { Kurikulum }\end{array}$ & : Fakruroji, SP \\
\hline $\begin{array}{l}\text { Wakil Kepala Sekolah Bidang } \\
\text { Industri }\end{array}$ & : Rikmanto, SST \\
\hline $\begin{array}{l}\text { Kepala Program Teknik Instalasi } \\
\text { Tenaga Listrik }\end{array}$ & : Hamdan Amirudin, SE, ME \\
\hline $\begin{array}{l}\text { Kepala Program Teknik Kendaraan } \\
\text { Ringan }\end{array}$ & : Sutikno, ST \\
\hline Kepala Program Akuntansi & : Alfizar, SE \\
\hline $\begin{array}{l}\text { Kepala Program Administrasi } \\
\text { Perkantoran }\end{array}$ & : EKJ. Rachma Dewi, S.Pd \\
\hline Nomor Identitas Sekolah (NIS) & $: 400450$ \\
\hline $\begin{array}{l}\text { Nomor Pokok Sekolah Nasional } \\
\text { (NPSN) }\end{array}$ & : 202532229 \\
\hline Nomor Statistik Sekolah (NSS) & $: 402022222002$ \\
\hline Luas Tanah & $: \quad 3000 \mathrm{~m}^{2}$ \\
\hline Luas Bangunan & $: 1039 \mathrm{~m}^{2}$ \\
\hline Alamat Sekolah & : Jl. Raya Cikarang-Cibarusah Km 11 \\
\hline Desa & : Sindang Mulya \\
\hline Kecamatan & : Cibarusah \\
\hline Kabupaten & : Bekasi \\
\hline Provinsi & : Jawa Barat \\
\hline Kode Pos & $: 17340$ \\
\hline Telepon & : $021-89954016$ \\
\hline Email & : smk abdinegara2cibarusah@yahoo.co.id \\
\hline Status Sekolah & : Swasta \\
\hline Nama Yayasan & : Yayasan Pendidikan Abdi Negara \\
\hline Tahun Berdiri & : 2004 \\
\hline Tanggal Berdiri & : 19 Juli 2004 \\
\hline Akreditasi & : Terakreditasi A \\
\hline $\begin{array}{l}\text { Penerbit Surat/Di Tandatangani } \\
\text { oleh }\end{array}$ & $\begin{array}{ll}\text { Dinas Pendidikan/Kepala } \\
\text { Pendidikan }\end{array}$ \\
\hline Surat Keputusan & $: \quad 02.00 / 694 / \mathrm{BAP}-\mathrm{SM} / \mathrm{XII} / 2015$ \\
\hline Penerbit SK/Di Tandatangani oleh & $\begin{array}{l}\text { Badan Akreditasi Provinsi - Sekolah } \\
\text { Menengah }\end{array}$ \\
\hline
\end{tabular}

TTabel 2 Program keahlian

\begin{tabular}{lcc}
\hline \multicolumn{1}{c}{ Kompetensi Keahlian } & Akreditasi & $\begin{array}{c}\text { Tahun } \\
\text { Akreditasi }\end{array}$ \\
\hline Teknik Instalasi Tenaga Listrik & $\mathrm{A}$ & 2115 \\
\hline $\begin{array}{l}\text { Teknik Otomotif Kendaraan } \\
\text { Ringan }\end{array}$ & $\mathrm{A}$ & 2115 \\
\hline Administrasi Perkantoran & $\mathrm{A}$ & 2115 \\
\hline Akuntansi & $\mathrm{A}$ & 2115 \\
\hline
\end{tabular}

Tabel 3. Jumlah siswa

\begin{tabular}{|c|c|c|c|c|}
\hline Program Studi & Tingkat I & $\begin{array}{c}\text { Tingkat } \\
\text { II }\end{array}$ & $\begin{array}{c}\text { Tingkat } \\
\text { III }\end{array}$ & Jumlah \\
\hline $\begin{array}{l}\text { Teknik Instalasi } \\
\text { Tenaga Listrik }\end{array}$ & 36 & 62 & 53 & 151 \\
\hline $\begin{array}{l}\text { Teknik } \\
\text { Otomotif } \\
\text { Kendaraan } \\
\text { Ringan }\end{array}$ & 58 & 115 & 90 & 263 \\
\hline $\begin{array}{l}\text { Administrasi } \\
\text { Perkantoran }\end{array}$ & 29 & 26 & 26 & 81 \\
\hline Akuntansi & 45 & 52 & 55 & 152 \\
\hline Jumlah & 168 & 255 & 224 & 647 \\
\hline
\end{tabular}

Tabel 4. Jumlah rombongan belajar

\begin{tabular}{llccc}
\hline \multirow{2}{*}{ Program Studi } & \multicolumn{3}{c}{ Tingkat } & \multirow{2}{*}{ Jumlah } \\
\cline { 2 - 5 } & I & II & III & 5 \\
\hline $\begin{array}{l}\text { Teknik Instalasi Tenaga } \\
\text { Listrik }\end{array}$ & 1 & 2 & 2 & 8 \\
\hline $\begin{array}{l}\text { Teknik Otomotif } \\
\text { Kendaraan Ringan }\end{array}$ & 2 & 3 & 3 & 3 \\
\hline Administrasi Perkantoran & 1 & 1 & 1 & 6 \\
\hline Akuntansi & 2 & 2 & 2 & $\mathbf{2 2}$ \\
\hline \multicolumn{1}{c}{ Jumlah } & $\mathbf{6}$ & $\mathbf{8}$ & $\mathbf{9}$ & \\
\hline
\end{tabular}


Tabel 5. Jumlah ruang kelas

\begin{tabular}{lcc}
\hline \multicolumn{1}{c}{ Kualifikasi } & Jumlah & Persen \\
\hline Baik & 21 & $100 \%$ \\
\hline Rusak Ringan & - & - \\
\hline Rusak Berat & - & - \\
\hline Total & $\mathbf{4 1}$ & $\mathbf{1 0 0 \%}$ \\
\hline
\end{tabular}

Tabel 6. Laboratorium dan ruang praktek

\begin{tabular}{lcc}
\hline \multicolumn{1}{c}{ Jenis Ruang } & Luas $\left(\mathbf{M}^{\mathbf{2}}\right)$ & Kondisi \\
\hline Teknik Mesin & 100 & Baik \\
\hline Teknik Listrik & 68 & Baik \\
\hline Komputer & 82 & Baik \\
\hline
\end{tabular}

Tabel 7. Prestasi akademik (rata-rata UAN) tahun pelajaran 2015/2016

\begin{tabular}{lc}
\hline \multicolumn{1}{c}{ Mata Diklat } & Nilai Rata-rata \\
\hline Bahasa Indonesia & 5,92 \\
\hline Matematika & 6,81 \\
\hline Bahasa Inggris & 6,77 \\
\hline Produktif & 8,06 \\
\hline
\end{tabular}

Tabel 8. Jumlah guru berdasarkan kulifikasi

\begin{tabular}{lc}
\multicolumn{1}{c}{ Kualifikasi } & Jumlah \\
\hline Doktor (S-3) & - \\
\hline Magister (S-2) & 3 \\
\hline Sarjana (S-1) & 34 \\
\hline Sarjana Muda (D-III) & 1 \\
\hline Diploma II (D-II) & 3 \\
\hline Diploma I (D-I) & - \\
\hline SLTA $\quad$ Total & - \\
\hline \multicolumn{2}{c}{} \\
\hline
\end{tabular}

Tabel 9. Jumlah guru berdasarkan status

\begin{tabular}{cc}
\hline Kualifikasi & Jumlah \\
\hline Guru Tetap Yayasan & 10 \\
\hline Guru Negeri (PNS) & - \\
\hline Guru Tidak Tetap (Honorer) & 31 \\
\hline Total & $\mathbf{4 1}$
\end{tabular}

bekal melamar pekerjaan. Oleh karena itu, peguasaan Microsoft Power Point sangat penting dalam proses belajar mengajar pada saat ini. Namun siswa-siswa SMK Abdi Negara 2 saat ini masih banyak yang belum menguasai aplikasi-aplikasi tersebut terutama aplikasi Power Point.

\section{H. Lokasi Mitra}

Pengabdian kepada masyarakat ini dilakukan di SMK Abdi Negara 2 Cibarusah yang berlokasi di Jl. Raya Cikarang Cibarusah Km 11, Desa Sindang Mulya, Kecamatan Cibarusah, Provinsi Jawa Barat.

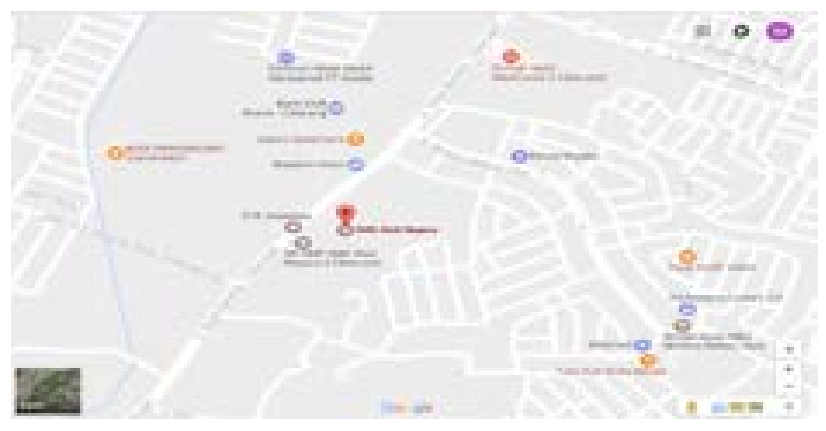

Gambar 2. Lokasi PKM

\section{SIMPULAN}

Kegiatan pelatihan yang telah dilaksanakan pada tanggal 10-11 April 2019 dapat disimpulkan bahwa kegiatan pelatihan ini memberikan pengetahuan mengenai aplikasi Microsoft Power Point 2007 dalam pembuatan slide presentasi yang menarik. Para peserta terlihat sangat antusias mengikutinya karena materi pelatihan sesuai dengan kebutuhan peserta. Keingintahuan peserta sangat besar, hal ini menjadikan materi pelatihan dapat tersampaikan secara keseluruhan. Nantinya, materi pelatihan ini dapat diterapkan dalam kegaiatan pengajaran sehingga proses belajar dan mengajar dapat lebih efektif dan berkualitas.

\section{DAFTAR PUSTAKA}

Andi, Panduan Praktis Microsoft Power Point. Semarang : Wahana Komputer, 2007

Fitria, Hendra. Step by Step Membuat Presentasi dengan Power Point 2007. Bandung: CV Arfino Raya, 2009.

Daryanto, Media Pembelajaran. Yogyakarta : Gava Media, 2010.

Andy, Perbedaan Microsoft Power Point 2003, 2007, 2010. Surakarta, 2010.

Purnomo, Catur Hadi, Panduan Belajar Otodidak Microsoft Powerpoint 2007, Jakarta: Media Kita, 2008 